\title{
Corrosion Behaviour of a Silane Protective Coating for NdFeB Magnets in Dentistry
}

\author{
Luigi Calabrese, ${ }^{1}$ A. Caprì, ${ }^{1}$ F. Fabiano, ${ }^{1}$ L. Bonaccorsi, ${ }^{1}$ \\ C. Borsellino, ${ }^{2}$ and Edoardo Proverbio ${ }^{1}$ \\ ${ }^{1}$ Department of Electronic Engineering, Industrial Chemistry and Engineering, University of Messina, Contrada di Dio, \\ 98166 Messina, Italy \\ ${ }^{2}$ Department of Civil Engineering, Computing, Construction, Environmental and Applied Mathematics, \\ University of Messina, Contrada di Dio, 98166 Messina, Italy
}

Correspondence should be addressed to Luigi Calabrese; lcalabrese@unime.it

Received 30 June 2015; Revised 3 August 2015; Accepted 20 August 2015

Academic Editor: Ksenija Babic

Copyright (C) 2015 Luigi Calabrese et al. This is an open access article distributed under the Creative Commons Attribution License, which permits unrestricted use, distribution, and reproduction in any medium, provided the original work is properly cited.

The corrosion behavior of coated and uncoated Ni/Cu/Ni rare earth magnets was assessed at increasing steps with a multilayering silanization procedure. Magnets' durability was analyzed in Fusayama synthetic saliva solution in order to evaluate their application in dental field. Corrosion performance was evaluated by using polarization and electrochemical impedance spectroscopy in synthetic saliva solution up to 72 hours of continuous immersion. The results show that the addition of silane layers significantly improved anticorrosion properties. The coating and aging effects, in synthetic saliva solution, on magnetic field were evaluated by means of cyclic force-displacement curves.

\section{Introduction}

Miniaturized NdFeB magnets have showed improved magnetic properties in comparison with samarium-cobalt magnetic alloys. The lack of corrosion resistance in climate and corrosive environment affects their long-term durability. This was mainly due to $\mathrm{NdFeB}$ magnet microstructure, which is constituted by 3 phases: a main phase $\Phi\left(\mathrm{Nd}_{2} \mathrm{Fe}_{14} \mathrm{~B}\right), \eta$ phase $\left(\mathrm{Nd}_{1}+\epsilon \mathrm{Fe}_{4} \mathrm{~B}_{4}\right)$, and Nd-rich phase $\left(\mathrm{Nd}_{4} \mathrm{Fe}\right)$ [1]. In the presence of an electrolyte solution, different electrochemical potentials promote galvanic corrosion, mainly within $\mathrm{Nd}$ rich phase. Low corrosion resistance causes mechanical deterioration, modification of the magnetic properties, and release of cytotoxic agents [2-4].

NdFeB magnets were introduced in 1980s and their use was extended in different fields for electric, electronic, electrochemical, and medical devices [3]. In particular, in orthodontic field, magnet applications have been included in space closures, extrusion of damaged teeth, eruption of impacted teeth, and similar applications. The interest in magnetic orthodontic systems was due to the need of generating a continuous and low intensity force in order to obtain biological teeth movements, such as tipping, movement, straightening root, rotation, extrusion, and intrusion [5-7].

In literature, numerous attempts are described in order to obtain an improvement of $\mathrm{NdFeB}$ magnets' durability, such as deposition of different coatings or the addition of alloying elements to the metal matrix [8-10]. Nevertheless, the methods proposed often deteriorate the magnetic properties and the adopted protective coatings still require an optimization for long-time applications.

In the present work, the deposition of the silane coating was performed using dip sol-gel technique. The influence of the coating on magnetic properties during aging time in synthetic Fusayama saliva solution at $\mathrm{pH} 5.5$ was evaluated. Moreover, the results underline that the multilayer coating does not affect the magnetic force of $\mathrm{NdFeB}$ magnets though it prevents corrosion degradation in solution. Thus potentially the limiting aspects precluding the use of $\mathrm{NdFeB}$ magnets in orthodontic and prosthodontic applications can be overcome by using organic-inorganic agents as surface coating materials. 
The effect of the number of silane layers was investigated by looking at the electrochemical behavior in potentiodynamic polarization tests and EIS measurements performed in the synthetic saliva solution at prolonged exposure time. Cyclic force-displacement curves were performed, allowing evidence of corrosion effect on magnets' flux density.

The results underline that the multilayer coating does not affect the magnetic force of NdFeB magnets. Furthermore the limiting corrosion aspects precluding the use of $\mathrm{NdFeB}$ magnets in orthodontic and prosthodontic applications can be overcome by using organic-inorganic agents as surface coating materials.

\section{Experimental Part}

$\mathrm{NdFeB}$ nickel-copper-nickel plated disk shaped magnets were obtained by commercial source. The diameter of the disks was $10 \mathrm{~mm}$ and the thickness was $5 \mathrm{~mm}$. The silane formulation used in this work, as a filming agent, was $\mathrm{N}$ propyltrimethoxysilane supplied by Sigma Aldrich (purum > 97\%).

To obtain reactive groups on the silane chains, an acid catalyzed hydrolysis at $\mathrm{pH} 4$ was performed in the presence of acetic acid. The hydrolysis was carried out in an alcoholic solution mixed with distilled water (ethanol/water/silane $90 / 5 / 5 \% \mathrm{v} / \mathrm{v}$ ). The solution was then magnetically stirred, at room temperature, for $24 \mathrm{~h}$. The layering method used was dip-coating technique through a sequence of deposition (3 minutes) and drying $\left(20\right.$ minutes at $\left.60^{\circ} \mathrm{C}\right)$. Four types of coated samples were prepared: $0,10,20$, and 30 silane layers coated magnets (identified as SL0, SL10, SL20, and SL30 samples).

An assessment of the external morphology of the coating was carried out by using a 3D microscope (Hirox $\mathrm{KH}$ 8700) and Focused Ion Beam Scanning Electron Microscopy (FIB-SEM Crossbeam Zeiss). In order to evaluate the surface degradation induced by corrosion phenomena, micrographic examinations were carried out after 72 hours of immersion.

Fusayama synthetic saliva was composed from $\mathrm{KCl}(0.9 \mathrm{~g} /$ $\mathrm{L}), \mathrm{NaCl}(0.4 \mathrm{~g} / \mathrm{L}), \mathrm{CaCl}_{2} \cdot 2 \mathrm{H}_{2} \mathrm{O}(0.796 \mathrm{~g} / \mathrm{L}), \mathrm{NaH}_{2} \mathrm{PO}_{4} \cdot 2 \mathrm{H}_{2} \mathrm{O}$ $(0.69 \mathrm{~g} / \mathrm{L})$, and $\mathrm{CO}\left(\mathrm{NH}_{2}\right)_{2}$ (urea $\left.1 \mathrm{~g} / \mathrm{L}\right)$. In order to evaluate the surface degradation induced by corrosion phenomena, micrographic examinations, by Hirox KH-8700 3D Digital Microscope, were carried out after 72 hours of immersion.

DC polarization and EIS measurements were carried out using a PAR VersaSTAT 4 potentiostat, equipped with Frequency Response Analyzer (FRA). All the measurements were performed at $37^{\circ} \mathrm{C}$ in an aerated Fusayama synthetic saliva solution (exposed area about $0.5 \mathrm{~cm}^{2}$ ). The anodic and cathodic polarization curves, according to ISO 17475 standard, were recorded using a sweep potential test in the range of $\pm 1,500 \mathrm{mV}$ with respect to open circuit potential, with a scanning rate of $1 \mathrm{mV} / \mathrm{s}$. Three potentiodynamic polarization tests were repeated for each sample. All potentials were referred to $\mathrm{Ag} / \mathrm{AgCl}$ electrode.

The impedance measurements were carried out at Open Circuit Potential (OCP) with a voltage amplitude of $10 \mathrm{mV}$
TABLE 1: Experimental set-up.

\begin{tabular}{|c|c|c|c|c|}
\hline Code & SL0 & SL10 & SL20 & SL30 \\
\hline Support & \multicolumn{4}{|c|}{$\mathrm{Ni} / \mathrm{Cu} / \mathrm{Ni}$ plated NdFeB magnet } \\
\hline $\begin{array}{l}\text { Number of } \\
\text { silane layers }\end{array}$ & 0 & 10 & 20 & 30 \\
\hline $\begin{array}{l}\text { Polarization } \\
\text { test }\end{array}$ & \multicolumn{4}{|c|}{$\begin{array}{l}\text { (i) } 72 \mathrm{~h} \text { of immersion in Fusayama synthetic saliva } \\
\text { (ii) } \pm 1,500 \mathrm{mV} \text { OCP } \\
\text { (iii) Scanning rate of } 1 \mathrm{mV} / \mathrm{s}\end{array}$} \\
\hline
\end{tabular}

(i) $72 \mathrm{~h}$ of immersion in Fusayama synthetic saliva

EIS test (ii) Voltage amplitude of $10 \mathrm{mV}$

(iii) Frequency range from $0.05 \mathrm{~Hz}$ to $100 \mathrm{kHz}$

Magnetic (i) $72 \mathrm{~h}$ of immersion in Fusayama synthetic saliva

force (ii) Crosshead speed of $0.05 \mathrm{~mm} / \mathrm{seconds}$

and a frequency range from $0.05 \mathrm{~Hz}$ to $100 \mathrm{kHz}$ (20 points for each frequency decade were acquired).

In order to simulate the use in a magnetic orthodontic system, the attractive force of micro $\mathrm{NdFeB}$ magnets was evaluated by using a universal testing machine $(2.5 \mathrm{kN}$, zwickiLine) with a $50 \mathrm{~N}$ load-cell with a sensibility of $0.001 \mathrm{~N}$. The crosshead speed was set at $0.05 \mathrm{~mm} /$ second. The lower magnet was fixed through clamping, while in the upper mounting jig magnet was fixed by a ceramic nonmagnetic system. The tests on the magnetic force have been carried out on SL0, SL10, SL20, and SL30 samples. A total of 5 measurements were performed for each magnet batch, after 0 and 72 hours of aging in synthetic Fusayama saliva solution at $\mathrm{pH}$ 5.5 , to investigate corrosion effects on magnetic properties. A schematic experimental set-up with detailed test conditions is reported in Table 1.

\section{Results and Discussion}

The cyclic force-displacement curves, during aging in simulated saliva solution at 0 and 72 hours for miniaturized $\mathrm{NdFeB}$ magnets, with and without silane coating, were presented in Figure 1.

The cyclic force-displacement curves permitted analysis if the flux density was affected by the aging in Fusayama solution and eventually corrosion damage effects. In fact, when magnet corrodes, the loss of crystal grains detached from the matrix could induce a different alignment of magnetic domains resulting in changes of maximum force value.

The asymptotes were completely reproducible as shown in the loading and unloading phases of the curves both for NdFeB magnets after 0 hours (Figure 1(a)) and after 72 hours (Figure 1(b)) of aging in synthetic saliva solution.

Analyzing $F_{\max }$ for unaged samples, a progressive decrease of $F_{\max }$ value with increased thickness of silane layer was observed. In particular, SL30 sample evidences a decrease of $5 \%$ of $F_{\max }$. The slight difference of $F_{\max }$ in silanized magnets can be caused either by the crosslinking process which 


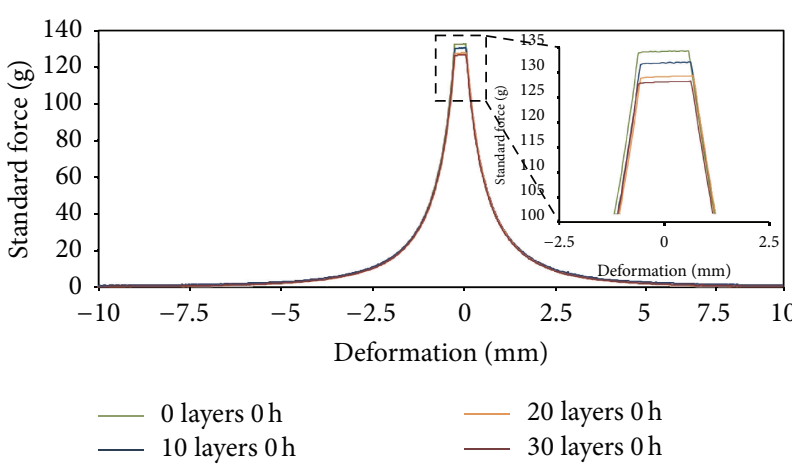

(a)

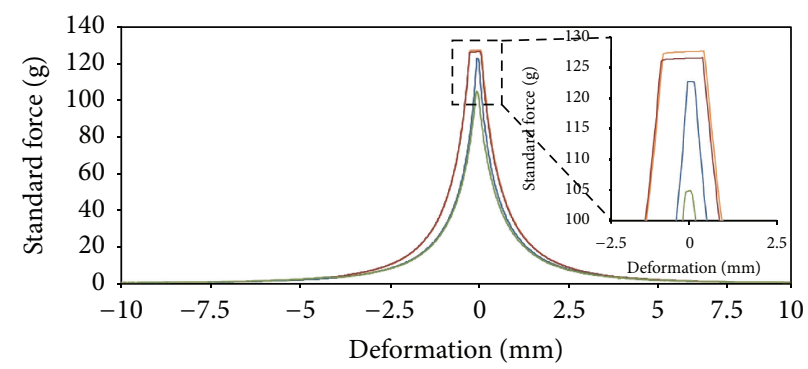

$\begin{array}{ll}-20 \text { layers } 72 \mathrm{~h} & -10 \text { layers } 72 \mathrm{~h} \\ -30 \text { layers } 72 \mathrm{~h} & 0 \text { layers } 72 \mathrm{~h}\end{array}$

(b)

FIgURE 1: Cyclic force-displacement curves between NdFeB magnets, in attraction mode, as a function of aging in simulated saliva environment: (a) no aging time; (b) after 72 hours of aging time.

involves a cyclic exposure of the magnet to temperature of $60^{\circ} \mathrm{C}$ or by the shielding action of the silane coating [11].

For magnets aged for 72 hours in Fusayama solution, the maximum force decreased dramatically. In fact, after 72 hours, magnets showed a reduction of about $20 \%$ of $F_{\max }$. This behaviour was related to the significant dissolution phenomena and the formation of large pits on the nickel surface. Silane coated magnets instead after 72 hours of aging exhibit no significant changes from the initial value (i.e., $7.2 \%$ for the 10 -layer magnets, $3.6 \%$ for the 20 -layer magnets, and $4.7 \%$ for the 30 -layer magnets). The SL10 evidenced a slight reduction due to a partial degradation of silane coating and subsequent substrate dissolution. By increasing the silane stratification, the barrier action becomes significant and consequently a better stability of the magnetic force can be obtained.

Maximum values recorded were generated at small separations; thus optimal orthodontic forces were obtained over the range of $-2.5 \mathrm{~mm}$ to $2.5 \mathrm{~mm}$.

The cathodic and the anodic branches of polarization curves of coated and uncoated magnets after 10 minutes of immersion in Fusayama solution are reported in Figure 2. The potentiodynamic polarization curve of SL0 sample exhibits an OCP of about $-0.100 \mathrm{~V}$ versus $\mathrm{Ag} / \mathrm{AgCl}$. Analyzing the cathodic branch of the curve, for all samples near to its OCP potential, the diffusion controlled oxygen reduction can be observed. Furthermore, at very low potential, hydrogen ion reduction or hydrogen evolution could take place. Additionally, oxygen reduction and hydrogen ion reduction always happen at the same time. At higher potential, oxygen reduction is the dominant cathodic reaction but at low potential hydrogen ion reduction represents the controlling reaction. All silane coated samples exhibit at middle potentials (about $-0.750 \mathrm{~V}$ versus $\mathrm{Ag} / \mathrm{AgCl}$ ) a quite similar slope indicating that the silane coating offers a barrier protection despite the chemical reactions on the surface [12].

It is possible to highlight that OCP is slightly influenced by the layering levels of the silane coatings, showing a progressive anodic shift at increasing thickness of the silane layer. The SL30 sample shows the highest OCP value $(\sim 40 \mathrm{mV}$ versus $\mathrm{Ag} / \mathrm{AgCl}$, about $150 \mathrm{mV}$ higher than SL0 sample).

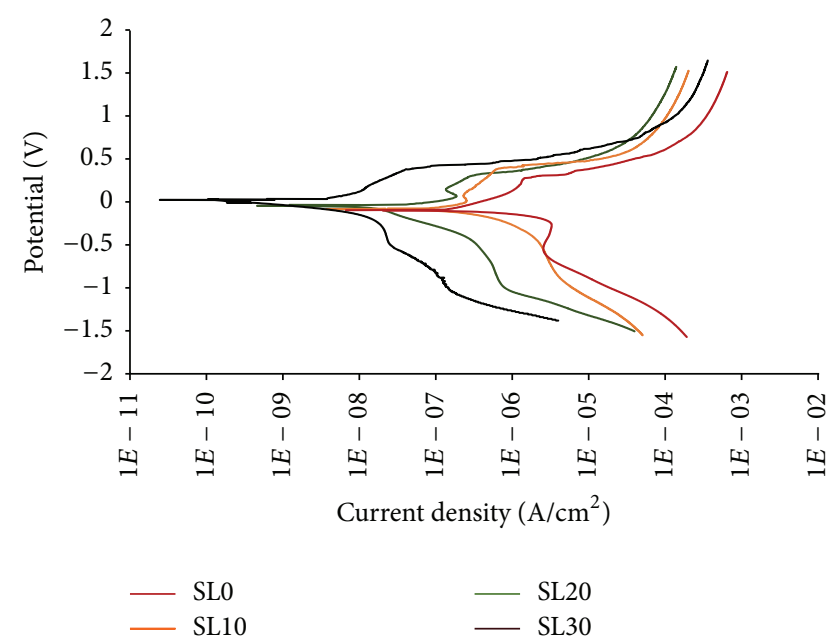

FIGURE 2: Cathodic and anodic branch of polarization curves of magnets after potential stabilization in Fusayama solution.

Furthermore, a decrease of the corrosion current density when the number of layers is increased can be observed. SL30 evidenced a current density three orders of magnitude lower than the SL0. This effect might be due to the good chemical interaction generated between the silane coating and the nickel outer layer of the $\mathrm{NdFeB}$ magnet [13]. The cause of the reduction of current density is most likely due to the mass transfer barrier generated by the coating that limits corrosive species (oxygen and hydrogen ion) to the magnet surface.

Similar behavior of the potentiodynamic curves was observed for the lower layering samples (SL10 and SL20), although for these specimens the barrier action of the silane coating was less effective considering that the anodic and cathodic currents were slightly higher than SL30 samples. Further consideration can be obtained evidencing that the breakdown potential shifts to higher potential at increasing number of silane layers. Highest resistance to localized attacks (which are activated at more noble potentials) was observed for SL30 sample evidencing a breakdown potential 


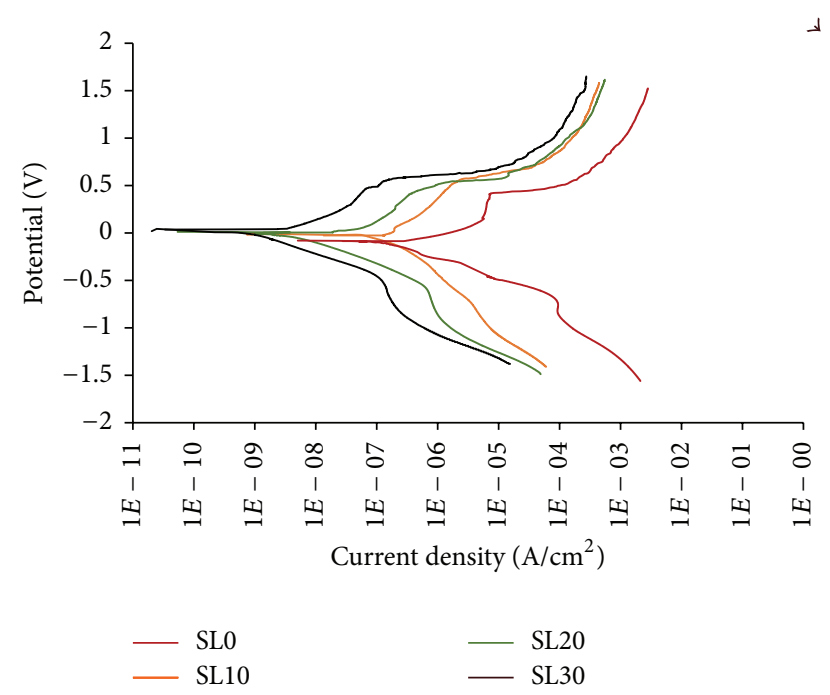

FIGURE 3: Cathodic and anodic branch of polarization curves of magnets after 72 hours of immersion in Fusayama solution.

of about $0.450 \mathrm{~V}$ versus $\mathrm{Ag} / \mathrm{AgCl}(100 \mathrm{mV}$ higher than SL0 one).

The cathodic and the anodic branches of the potentiodynamic polarization curves after $72 \mathrm{~h}$ of immersion in Fusayama solution are reported in Figure 3. The polarization trends are quite similar to those observed without aging. Again, the most promising electrochemical behavior was observed for SL30 which evidenced an efficient stability in Fusayama solution maintaining unvaried potentials, OCP at $\sim 0.040 \mathrm{~V}$ versus $\mathrm{Ag} / \mathrm{AgCl}$, and breakdown potential at $\sim 0.5 \mathrm{~V}$ versus $\mathrm{Ag} / \mathrm{AgCl}$.

SL10 and SL20 samples still evidenced a cathodic current density one order of magnitude lower than SL0 sample. This behavior indicates that the multilayer silanization of magnets is able to guarantee just acceptable barrier action at low layering steps. Instead, the SL30 sample, characterized by a thicker silane layer, after the immersion for $72 \mathrm{~h}$ in synthetic saliva solution, still demonstrated good anticorrosion performance, as identifiable by the significant reduction of anodic and cathodic currents in the investigated potential range. Furthermore, by analyzing the breakdown potential, all silane coated samples maintained a higher resistance to localized attack than SL0 sample. This consideration can be confirmed by observing the surface of the uncoated magnets and of the silanized magnets before and after potentiodynamic tests, as reported in Figure 4. The SL0 sample is characterized by numerous large pits distributed in all tested surfaces. Instead the SL30 does not evidence any significant degradation effect on its surface.

In Figure 5, surface morphology of pits in SL0 samples was evaluated by $3 \mathrm{D}$ scan profilometry, evidencing a pit depth of about $10 \mu \mathrm{m}$.

In Figure 6, the Bode plots (impedance modulus and phase versus frequency) of $\mathrm{NdFeB}$ magnets are reported at the increasing thickness of the silane layer after $10 \mathrm{~min}$ of immersion in synthetic saliva solution. Analyzing the trend of the impedance module, it is possible to confirm the behavior analyzed by polarization curves. SL0 magnet shows impedance values relatively low compared with the results observed for silane coated magnets. Best performance is shown by the SL30 samples which exhibit, at low frequencies, impedance value near to $10^{8} \mathrm{Ohms} \mathrm{cm}$ (about two orders of magnitude higher than SL20 systems and more than three orders of magnitude higher than the SL0 ones).

The presence of a single time constants (about 100$300 \mathrm{~Hz}$ ) for the SL30 and SL20 samples confirms the good protective action offered by this multilayer coatings due to sealing effects.

For the SL10 systems on the other hand this effect is less evident. Indeed, this sample shows two time constants (at $\sim 10^{2} \mathrm{~Hz}$ and at $\sim 1 \mathrm{~Hz}$ ). The first one, at high frequency, is related with the silane coating interphase. Instead, the second one, at lower frequencies, is related to the electrolyte/metal interface probably due to the water penetration through the coating [14]. This behavior indicates that samples having not sufficiently thick silane coating could be susceptible to significant corrosion phenomena, also at low immersion time in Fusayama solution. Increasing the thickness of the silane layer (SL20 and SL30), the coating barrier is more effective inducing better corrosion performances. At the same time the good interactions occurred between the metal surfaces and the silane film also induces a hydrophobic behavior on the surface of the coating [15] which limits their water absorption capacity aptitude and consequently hinders the electrochemical reaction on the metal-silane interphase.

Figure 7 shows the impedance plots after 72 hours of immersion for coated and uncoated magnets. The impedance modulus (Figure 7(a)), at low frequency, for SL10 and SL20 samples, decreased significantly after immersion in synthetic saliva solution. These samples with impedance values quite similar to uncoated samples revealed low durability performances of thin silane coating in this electrolyte media. Water easily reached the metal substrate reducing the double layer impedance and favoring localized corrosion phenomena. Only SL30 sample still evidenced a high impedance modulus compared with SL0 one, confirming its effective anticorrosion performances. After $72 \mathrm{~h}$ of immersion, the phase angles (Figure 7(b)) differ from those ones measured after 10 minutes.

Coated samples exhibit two time constants about $200 \mathrm{~Hz}$ and $1-0.1 \mathrm{~Hz}$. This behavior is probably due to the leakage of the saliva solution through the coating via the promotion of active pathways in correspondence of defects or pinholes [13]. At low frequency range, $1-0.1 \mathrm{~Hz}$, all magnets exhibited a time constant indicating that the electrochemical activity at the coating/substrate interface is taking place. The high phase angle at low frequency observed on these samples could be related to diffusion controlled processes at local nickel coating defects which stimulate pit formation and propagation [16].

The time constant at medium frequency is still evident. SL30 sample shows a phase angle of about $-60^{\circ}$ at $100 \mathrm{~Hz}$, indicating that the multilayer silane deposition induced an appreciable effect on the durability of the magnet, although the slight reduction of the impedance spectrum indicates that the activation of undercoating corrosion phenomena may be 


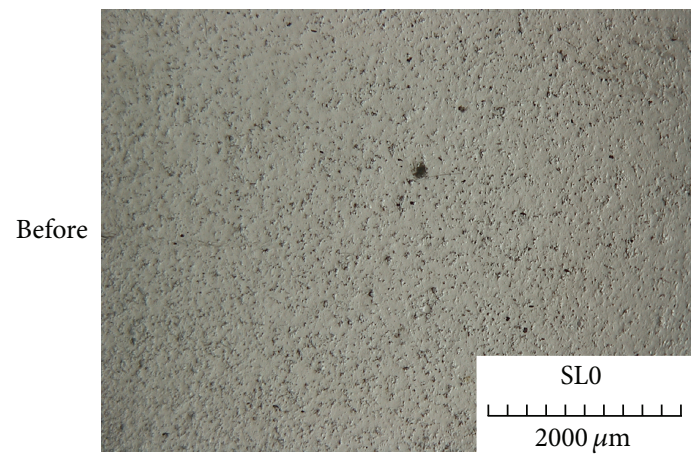

(a)

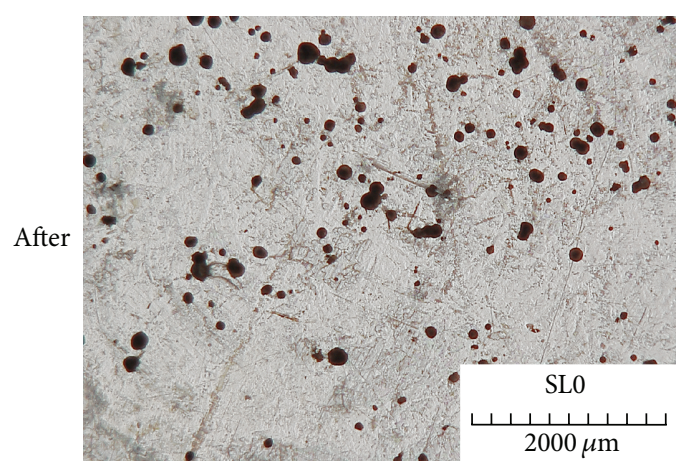

(c)

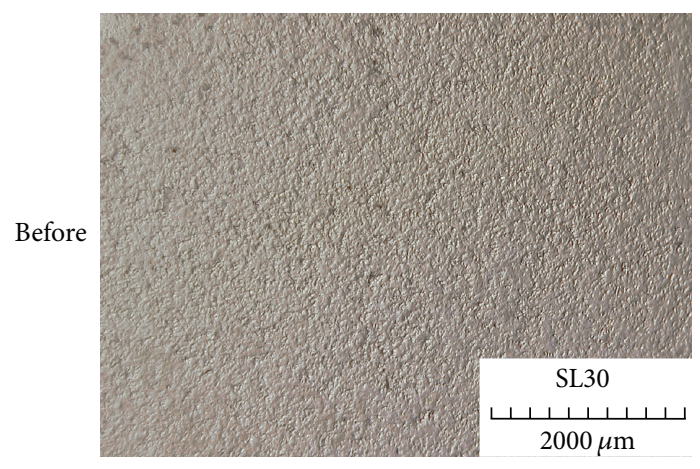

(b)

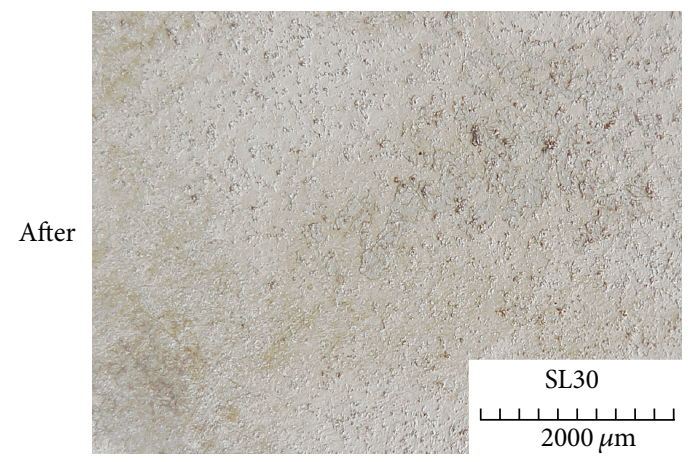

(d)

FIGURE 4: Stereomicroscopic images (50x) of the surface of the uncoated and SL30 silanized magnets before ((a) and (b), resp.) and after ((c) and (d), resp.) potentiodynamic measurements.

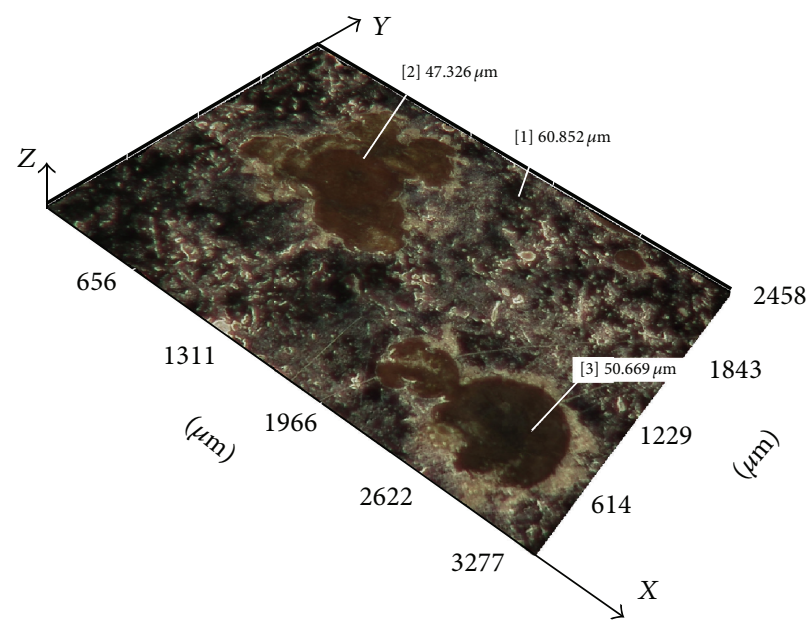

FIGURE 5: 3D scan profilometry of a pit in SL0 sample.

upcoming. Consequently, further efforts should be done to optimize the anticorrosive action of this type of coatings in order to be implemented in orthodontic application.

\section{Conclusions}

Electrochemical properties of silane coated and uncoated $\mathrm{Ni} / \mathrm{Cu} / \mathrm{Ni}$ rare earth magnets were evaluated at increased thickness of silane layer. The cyclic force-displacement curves permitted evidencing the changes in magnets' flux density due to corrosion effects. This test proves the durability of the coated samples in a Fusayama solution at pH 5.5. After 72 hours, silanized samples (SL10-SL30) showed no significant changes in $F_{\max }$ mean value, while SL0 samples evidenced a significant decrease of about $20 \%$. The corrosion behavior was studied by polarization and electrochemical impedance spectroscopy measurements, which were performed in synthetic saliva solution as a function of time. Polarization 


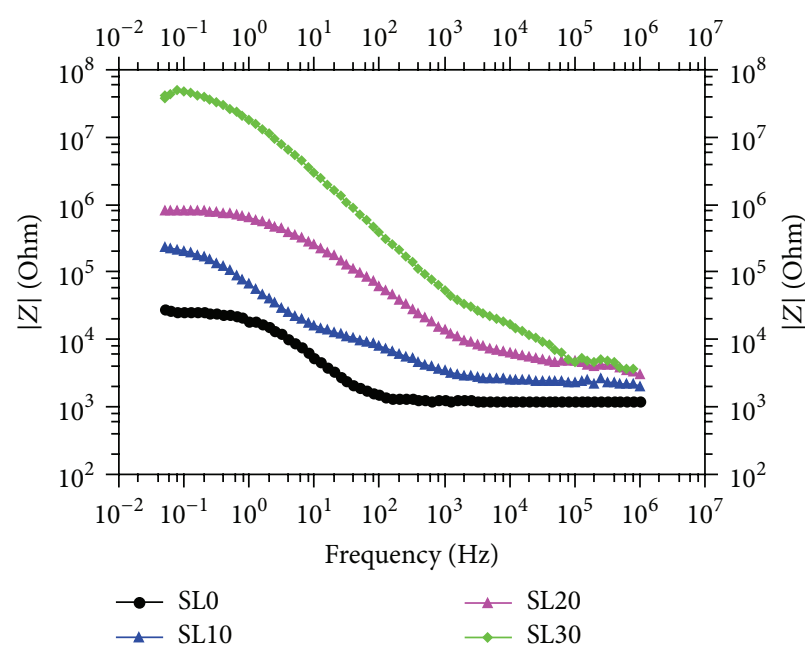

(a)

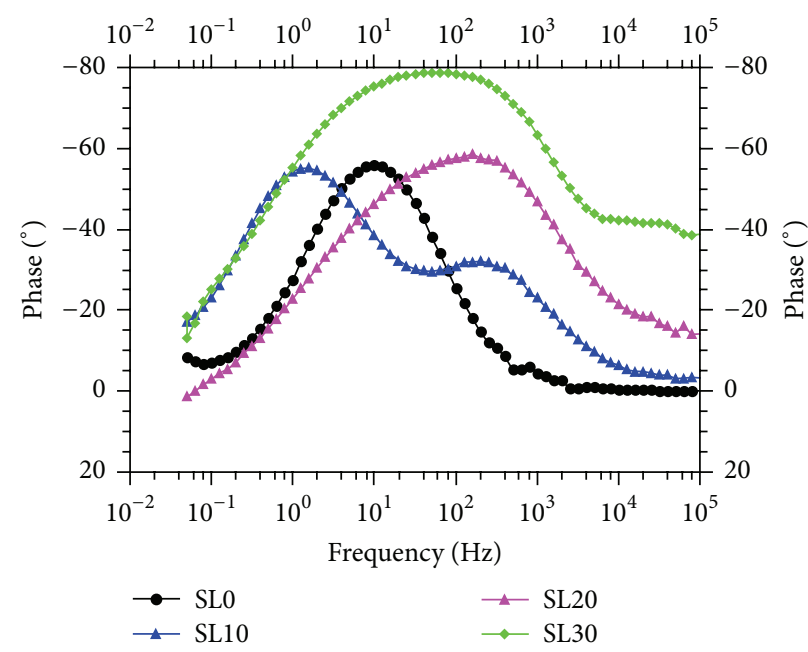

(b)

Figure 6: Bode plots (a) $|Z|$ and (b) phase plot at increasing silane layers after $10 \mathrm{~min}$ of immersion in synthetic saliva solution.

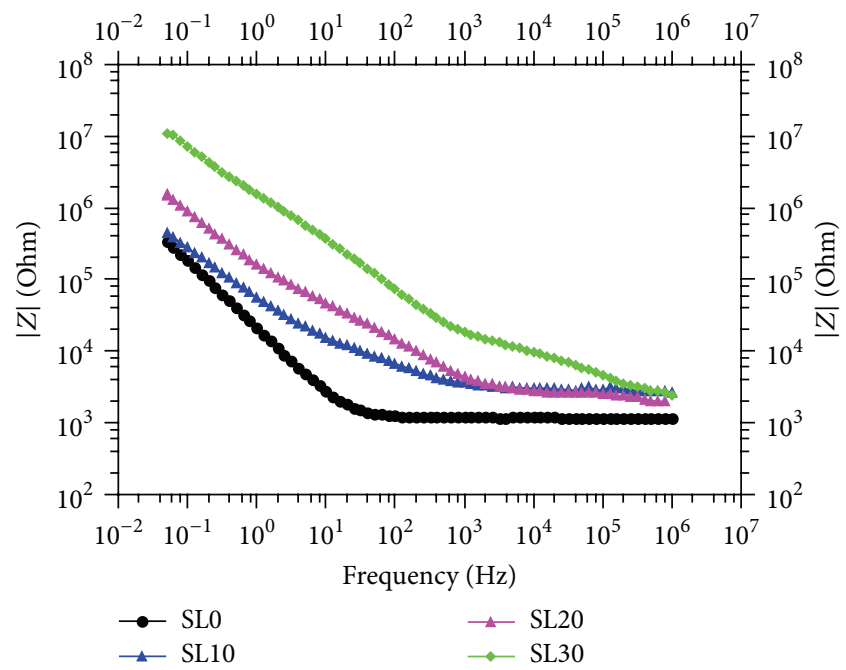

(a)

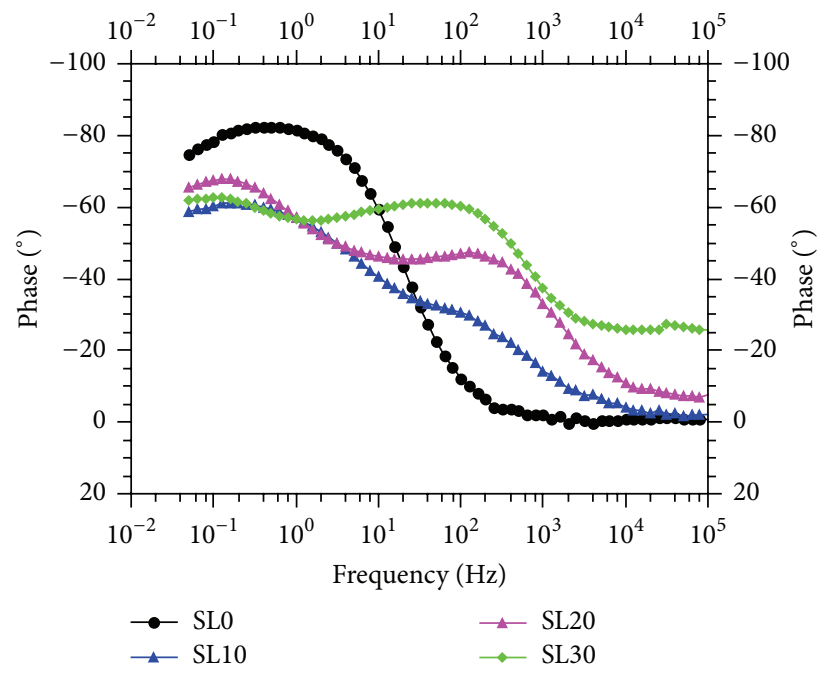

(b)

FIgURE 7: Bode plots (a) $|Z|$ and (b) phase at increasing silane layers after $72 \mathrm{~h}$ of immersion in synthetic saliva solution.

measurements showed a good performance for SL30 sample evidencing its efficient stability in Fusayama solution at a large applied potential range. The EIS measurements confirmed the good protective barrier capacity of 30 layers coating on the magnet in an applied frequency range.

\section{Conflict of Interests}

The authors declare that there is no conflict of interests regarding the publication of this paper.

\section{References}

[1] J. Jakubowicz, "Corrosion protection of nanocomposite $\mathrm{NdFeB} / \alpha$-Fe magnets," Journal of Alloys and Compounds, vol. 314, no. 1-2, pp. 305-308, 2001.
[2] F. T. Cheng, H. C. Man, W. M. Chan, C. W. Cheng, and W. O. Chan, "Corrosion protection of Nd-Fe-B magnets by bismaleimide coating," Journal of Applied Physics, vol. 85, no. 8, article $5690,1999$.

[3] J. M. Hu, X. L. Liu, J. Q. Zhang, and C. N. Cao, "Corrosion protection of Nd-Fe-B magnets by silanization," Progress in Organic Coatings, vol. 55, no. 4, pp. 388-392, 2006.

[4] Y. W. Song, H. Zhang, H. X. Yang, and Z. L. Song, "A comparative study on the corrosion behavior of $\mathrm{NdFeB}$ magnets in different electrolyte solutions," Materials and Corrosion, vol. 59, no. 10, pp. 794-801, 2008.

[5] W. R. Proffit and H. W. Fields, "Mechanical principles in orthodontic force control," in Contemporary Orthodontics, pp. 369-405, Mosby-Year Book, St. Louis, Mo, USA, 3rd edition, 2000 
[6] A. Saliba-Silva, R. N. Faria, M. A. Baker, and I. Costa, "Improving the corrosion resistance of $\mathrm{NdFeB}$ magnets: an electrochemical and surface analytical study," Surface and Coatings Technology, vol. 185, no. 2-3, pp. 321-328, 2004.

[7] F. Fabiano, F. Celegato, A. Giordano et al., "Assessment of corrosion resistance of $\mathrm{Nd}-\mathrm{Fe}-\mathrm{B}$ magnets by silanization for orthodontic applications," Physica B: Condensed Matter, vol. 435, pp. 92-95, 2014.

[8] A. Ali, A. Ahmad, and K. M. Deen, "Multilayer ceramic coating for impeding corrosion of sintered NdFeB magnets," Journal of Rare Earths, vol. 27, no. 6, pp. 1003-1007, 2009.

[9] S. Mao, H. Yang, Z. Song, J. Li, H. Ying, and K. Sun, "Corrosion behaviour of sintered $\mathrm{NdFeB}$ deposited with an aluminium coating," Corrosion Science, vol. 53, no. 5, pp. 1887-1894, 2011.

[10] W. He, L. Zhu, H. Chen et al., "Electrophoretic deposition of graphene oxide as a corrosion inhibitor for sintered NdFeB," Applied Surface Science, vol. 279, pp. 416-423, 2013.

[11] L. Calabrese, L. Bonaccorsi, C. Borsellino, A. Caprì, F. Fabiano, and E. Proverbio, "Electrochemical impedance spectroscopy behaviour of $\mathrm{NdFeB}$ coated magnets in saliva solution for orthodontic applications," Solid State Phenomena, vol. 227, pp. 515-518, 2015.

[12] D. Zhu and W. J. van Ooij, "Corrosion protection of AA 2024-T3 by bis-[3-(triethoxysilyl)propyl]tetrasulfide in sodium chloride solution. Part 2: mechanism for corrosion protection," Corrosion Science, vol. 45, no. 10, pp. 2177-2197, 2003.

[13] D. Yang, C. Liu, X. Liu, M. Qi, and G. Lin, "EIS diagnosis on the corrosion behavior of TiN coated NiTi surgical alloy," Current Applied Physics, vol. 5, no. 5, pp. 417-421, 2005.

[14] M. F. Montemor, A. M. Simões, M. G. S. Ferreira, B. Williams, and H. Edwards, "Corrosion performance of organosilane based pre-treatments for coatings on galvanized steel," Progress in Organic Coatings, vol. 38, no. 1, pp. 17-26, 2000.

[15] L. Calabrese, L. Bonaccorsi, A. Caprì, and E. Proverbio, "Electrochemical behavior of hydrophobic silane-zeolite coatings for corrosion protection of aluminum substrate," Journal of Coatings Technology Research, vol. 11, no. 6, pp. 883-898, 2014.

[16] M. F. Montemor, A. M. Cabral, M. L. Zheludkevich, and M. G. S. Ferreira, "The corrosion resistance of hot dip galvanized steel pretreated with Bis-functional silanes modified with microsilica," Surface and Coatings Technology, vol. 200, no. 9, pp. 28752885, 2006. 

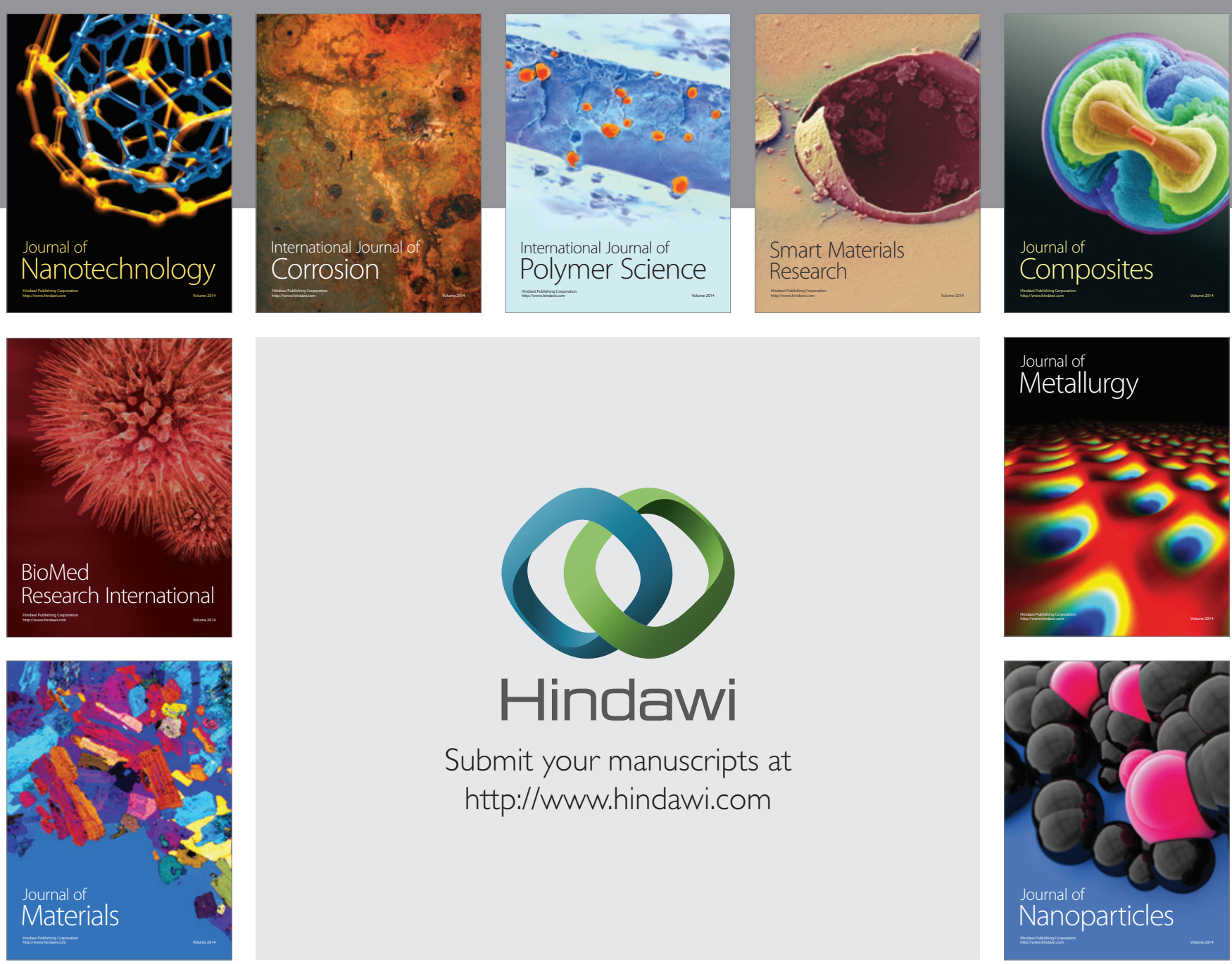

Submit your manuscripts at http://www.hindawi.com
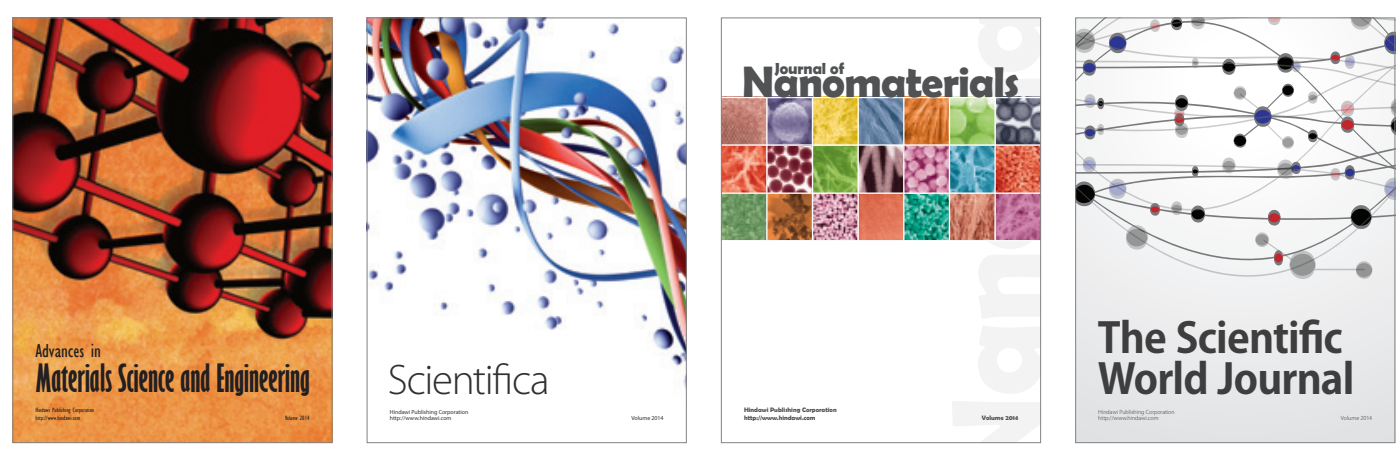

\section{The Scientific World Journal}
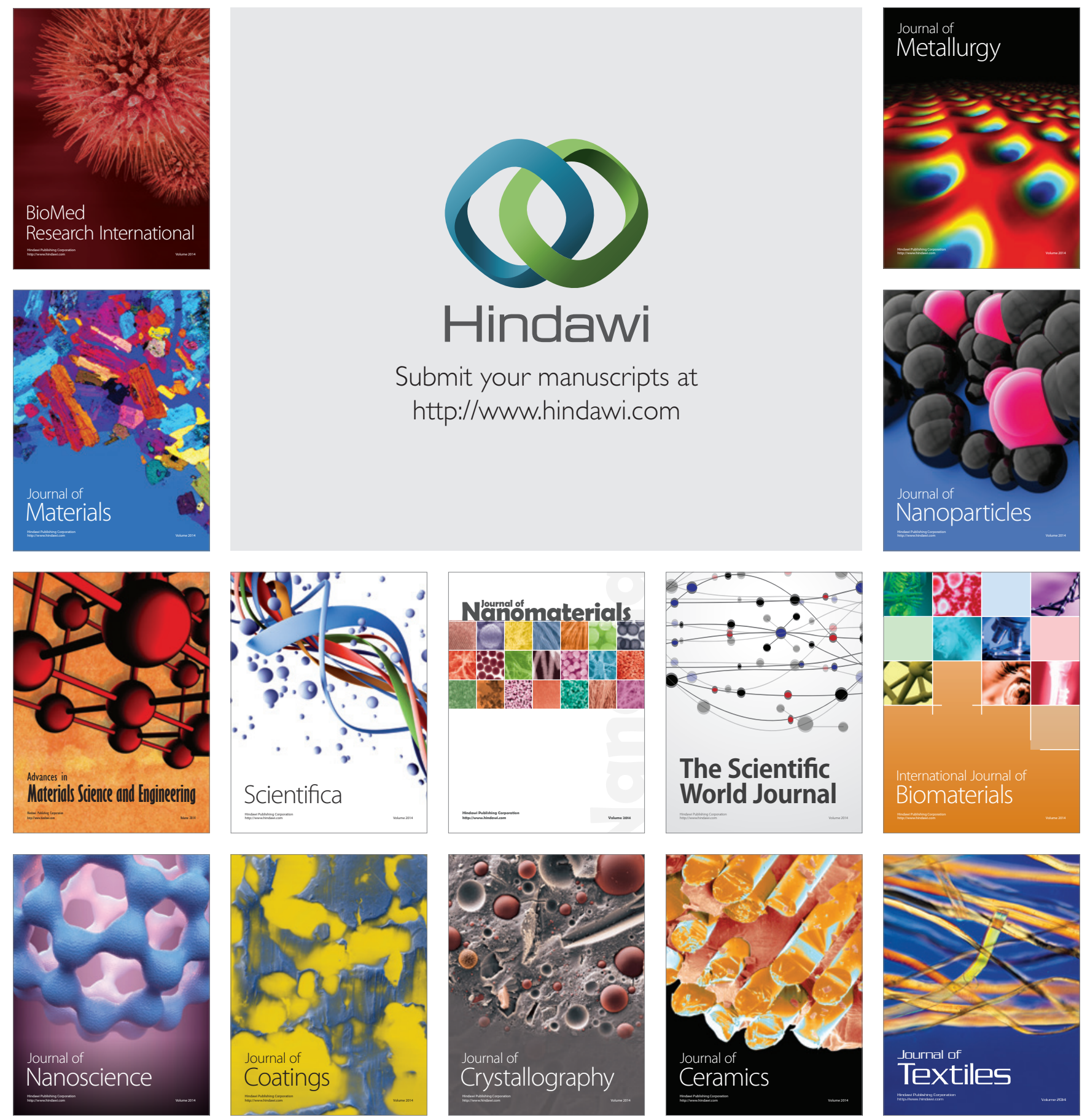